\title{
Intergenerational Ethnic Mobility among Canadian Aboriginal Populations in 2001
}

\author{
Norbert Robitaille \\ Department of Demography \\ Université de Montréal \\ Montréal, Québec, Canada \\ Éric Guimond \\ Strategic Research and Analysis Directorate \\ Indian and Northern Affairs Canada \\ Adjunct Research Professor \\ Department of Sociology \\ University of Western Ontario \\ London, Ontario, Canada \\ E-mail: guimonde@ainc-inac.gc.ca
}

\begin{abstract}
Alexandre Boucher
Institut de recherche en santé et en sécurité du travail

Montréal, Québec, Canada
\end{abstract}

\begin{abstract}
This article deals with the contribution of intergenerational ethnic mobility to the demographic reproduction of the Aboriginal groups in Canada: the North American Indians, the Métis and the Inuit. To this effect, it attempts to see if children in husband/wife census families keep the identity of their parents. As expected, children from endogamous couples generally keep their parents' identity. However, for most children from exogamous couples formed by an Aboriginal person and a non-Aboriginal person, the Aboriginal identity prevails over the non-Aboriginal identity. If Aboriginal identities were "not attractive" identities when declaring the ethnic affiliation of children in situations of exogamous unions, then the size of the Aboriginal population in Canada would be significantly smaller.
\end{abstract}

Key Words: Intergenerational ethnic mobility, Aboriginal population, Canada, identity, Aboriginal identity, transmission 


\section{Résumé}

Cet article examine en quoi la mobilité ethnique intergénérationnelle contribue à la reproduction démographique des groupes autochtones du Canada; c'est-àdire: Les Amérindiens, les Métis et les Inuits. Pour ce faire, l'article tente d'examiner si les enfants de familles de recensement époux et épouse gardent l'identité de leurs parents. Tel que prévu, les enfants issus de couples endogènes ont tendance à garder l'identité de leurs parents. Cependant, pour la plupart des enfants issus de couples exogènes se composant d'une personne autochtone et d'une personne non-autochtone, l'identité autochtone l'emporte sur l'identité non-autochtone. Si l'identité autochtone n'était pas une identité qui semble "attrayante" au moment de la déclaration de l'affiliation ethnique des enfants dans le cas d'unions exogènes, la population autochtones $d u$ Canada serait bien moindre.

Mots clés: Mobilité ethnique intergénérationnelle, population autochtone, Canada, identité, transmission

\section{Introduction}

In Canada, three Aboriginal groups are recognized by the Constitution: the North American Indians, the Métis and the Inuit. The North American Indian group, or First Nations, is essentially composed of two "subgroups": the Status Indians who are legally recognized as Indians under the Indian Act, and the Non-Status Indians who self-identify but are not entitled to be registered under this Act. The Métis group originates from the descendants of mixed couples formed when European explorers had children with Indians women, particularly so in the plains of Western Canada. A significant proportion of those descendants integrated neither in the Indian group nor in the non-Aboriginal group, and developed their own cultural identity. The last group, the Inuit, includes populations originating from the Arctic region, more isolated and often having kept their language, Inuktitut.

Table 1 shows the relative importance of these Aboriginal groups according to the Census of Canada, which is the only source of data that include all Aboriginal peoples. Given the many changes in the Canadian census to how data on Aboriginal groups has been collected through the years (Guimond 2009), the definition used here combines two indicators of affiliation with Aboriginal groups: origin and identity. The concept of origin refers to the ethnic or cultural group to which one's ancestors belonged, while the concept of identity designates the respondent's current ethnic affiliation or sense of belonging. Table 1 shows a majority of people reporting an Aboriginal origin

CSP 2010, 37.1-2: 151-174 


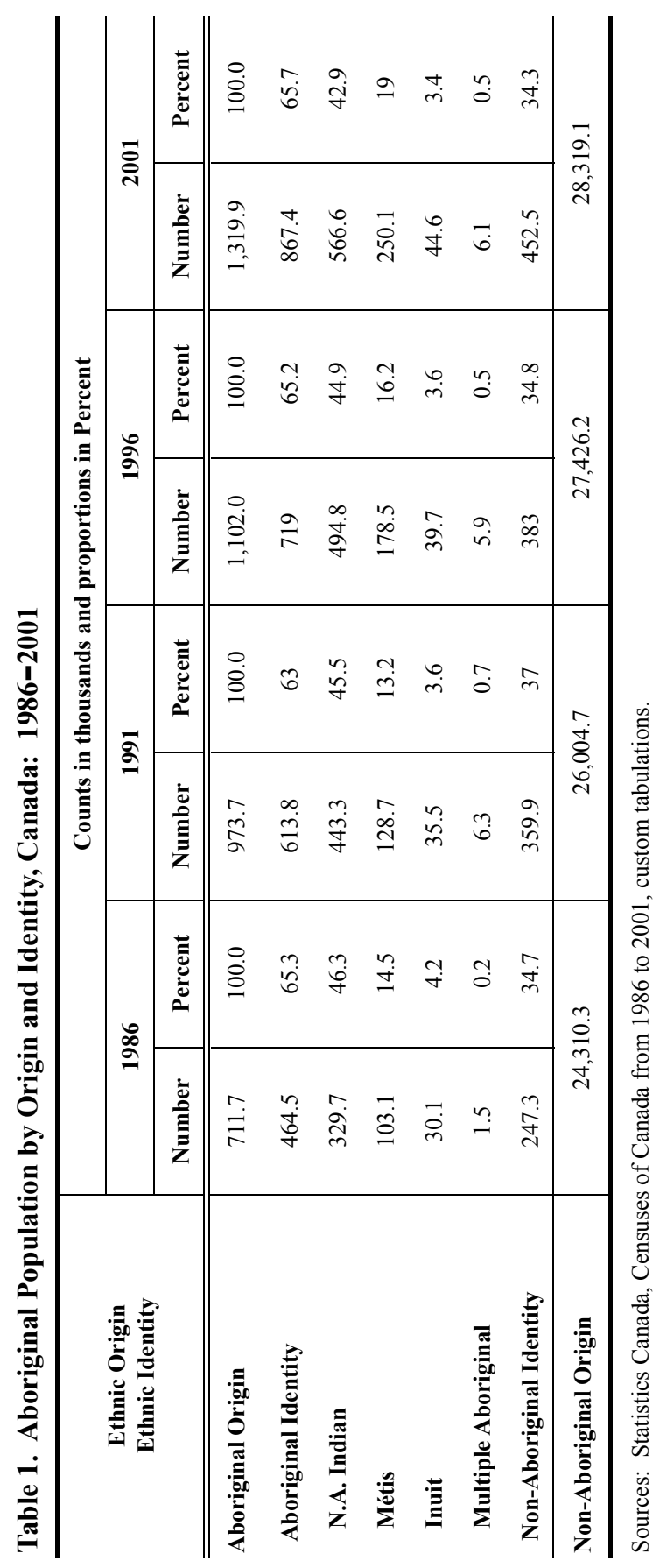


also declare an Aboriginal identity (65.7\% in 2001). About a third of people reporting an Aboriginal origin do not self-identify as Aboriginal. It can also be seen from this table that the population growth of the different Aboriginal groups is significant but uneven.

This growth is further illustrated in Figure 1, which shows the average annual growth rates for each intercensal between 1986 and 2001. Since the contribution of international migration may be considered nil and the quality of population coverage is relatively stable from census to census (Guimond 2003: 94-95), it could initially be concluded that such growths are subject only to the natural movement of births and deaths. But this is not the case: North American Indians and Métis have experienced growth rates which exceed the theoretical maximum rate of natural increase of $5.5 \%$ per year. This theoretical rate is obtained from the highest crude birth rate (60 per 1,000 persons) observed in exceptional conditions - a young population, marrying young and practising no form of contraception - from which is subtracted the lowest crude death rate ${ }^{1}$ (5 per 1,000 persons). Such a combination of a high birth rate and a low death rate has probably never been observed. Today, the highest national rates of natural increase in the world are about $3.5 \%$ per year. A population maintaining a growth rate of $5.5 \%$ per year doubles every 13 years. After a hundred years, that population would be more than 200 times larger than at the outset. A growth rate in excess of $5.5 \%$ cannot be explained by natural increase alone: phenomena other than births and deaths are obviously contributing to the increase.

In light of available information - natural increase, international migration and quality of population coverage in the census - Canada's Aboriginal population growth from 1986 to 2001 results, in variable proportions depending on the period and Aboriginal group, from changes in self-reporting of ethnic identity.

\section{The Issue}

Ethnic mobility is generally known as the phenomenon by which individuals change their ethnic affiliation. In relation to a group, ethnic mobility is a multidirectional phenomenon, composed of entries and exits that supply or tap the group. Such mobility of an individual from one group to another is called intragenerational ethnic mobility. However, there is another type of mobility that can occur during the children's first identification, called intergenerational ethnic mobility, which happens when parents and children do not have the same ethnic affiliation, most often when the two parents have a different ethnic identity. Because of this intergenerational mobility, an individual from one group can supply another group through his or her offspring. This type of ethnic mobility does not per se entail any ethnic transfer on the part of the child. Instead, it reflects a shift in ethnocultural affiliation across generations, i.e.

CSP 2010, 37.1-2: 151-174 
Intergenerational Ethnic Mobility among Canadian Aboriginal Populations in 2001

Figure 1

Average Annual Growth Rate by Aboriginal Identity, Canada: 1986-2001

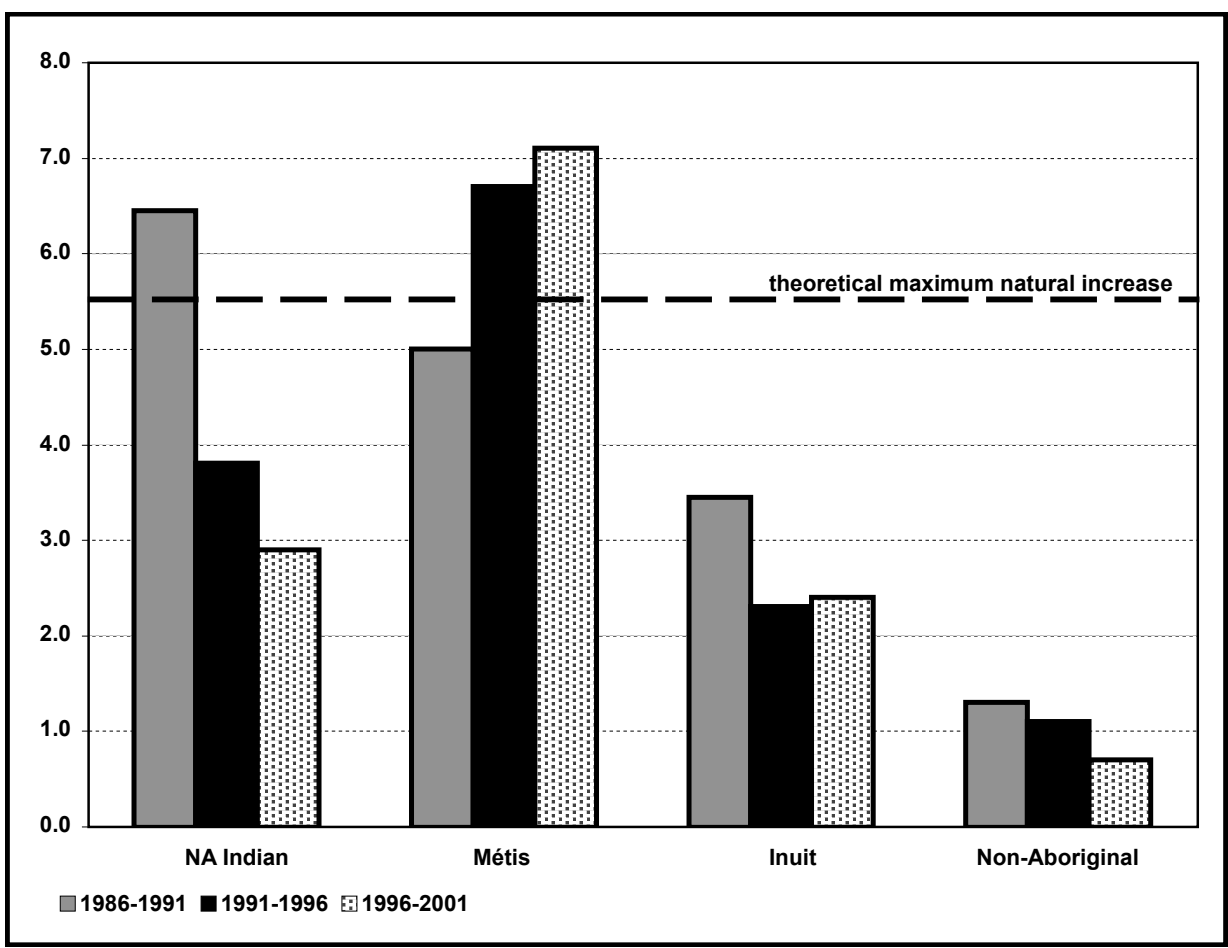

Source: Statistics Canada, Censuses of Canada, 1986 - 2001, custom tabulations. 
between parents and children. Practically speaking, intergenerational ethnic mobility is measured through the comparison of the ethnic identity of children to their parent's identity (individually or combined).

The classic equation for the demographic growth of a population defined by its ethnicity is enriched by the inclusion of these two mobilities.

$$
\mathrm{P}_{(\mathrm{t}+\mathrm{n})}=\mathrm{P}_{(\mathrm{t})}+\mathrm{B}-\mathrm{D}+\mathrm{M}+\beta
$$

If $\mathrm{P}_{(\mathrm{t})}$ and $\mathrm{P}_{(\mathrm{t}+\mathrm{n})}$ represent the population of ethnic group $\mathbf{A}$ at times $\mathrm{t}$ and $\mathrm{t}+\mathrm{n}$, and $\mathrm{B}, \mathrm{D}$ and $\mathrm{M}$ represent the births, deaths and net migration that renew it, we have the classic equation for the demographic growth of a population, with two differences. First, $\beta$ represents the net changes (entries minus exits) in ethnic affiliation, i.e. the product of intragenerational ethnic mobility. Secondly, the births $\mathrm{B}$ include those from parents not belonging to group A (positive component of intergenerational ethnic mobility) but exclude those born to parent(s) from group $\mathbf{A}$ who were reported to have an identity other than $\mathbf{A}$ (negative component of intergenerational ethnic mobility).

The goal of this article is to deal with the second of these two mobilities, intergenerational ethnic mobility. Building on existing demographic literature, we first discuss a different approach for the study of the demographic reproduction of a population defined by ethnicity. This theoretical discussion is followed by a descriptive analysis of patterns of intergenerational identification of children in Aboriginal families according to the 2001 Canadian census. We conclude our paper with an assessment of the contribution of intergenerational ethnic mobility to the size of the Aboriginal populations in 2001.

\section{Literature Review}

There is extensive sociological and anthropological literature on the topic of ethnicity, ethnic affiliation and affiliation changes ${ }^{2}$. However, what clearly emerges on reading the work of recognized contributors in the field (Gordon 1964; Barth 1969; Lieberson and Waters 1988; Alba 1990) is that demographic analysis, understood here as the measurement of the dimension and dynamics of population change, is not very developed. The significance of demographic analysis is nonetheless underscored.

“...in most situations the poly-ethnic systems we observe do entail quite complex processes of population movement and adjustment. It becomes clear that a number of factors other than human fertility and mortality affect the balance of numbers... Migration and conquest play an intermittent role in redistributing populations and changing their relations. But the 
Intergenerational Ethnic Mobility

among Canadian Aboriginal Populations in 2001

most interesting and often critical role is played by another set of processes that effect changes of the identity of individuals and groups...The analysis of the different factors involved in this balance is an important part of the analysis of the ethnic inter-relations in the area." (Barth 1969: 21-24)

The first demographic analysis of intragenerational ethnic mobility in Canada, which became a classic over the years, was written by Ryder (1955). The author explains the strange variations in the size of the German and Dutch origin populations observed between 1911 and 1941 by changes in self-reporting of origin, with the First and Second World Wars leading people with German ancestors to abandon their origin. Twenty years went by before ethnic mobility again became a topic of demographic interest, this time as part of work done on the topic of the linguistic assimilation of the French-origin population (Castonguay 1977; Henripin 1974).

Robitaille and Choinière (1987) were the first demographers to underscore the necessity of considering intragenerational and intergenerational ethnic mobilities in the demographic analysis of Aboriginal populations in Canada. Under the guidance of Robitaille, Guimond (2009, 2003, 1999) proposed a series of estimates of the intragenerational ethnic mobility of North American Indian, Métis and Inuit populations in Canada between 1986 and 2001. The highlight of his analysis is that ethnic mobility, like fertility, mortality and migration, is a component of the demographic growth of Indian and Métis populations, and sometimes the most significant component. In addition, this analysis also revealed that intragenerational ethnic mobility had a considerable impact on the evolution of demographic (average number of children per woman) and socio-economic (proportion of university graduates) characteristics of Aboriginal populations in Canada since the early 1980s.

In the United States, various researchers showed interest in the American Indians' exceptional demographic growth (Passel 1976; Passel and Berman 1986; Eschbach 1993; Passel 1996; Eschbach, Supple and Snipp 1998). They unanimously found that changes in self-reporting of ethnic and racial affiliation (i.e. intragenerational ethnic mobility) are sometimes the most significant component of demographic growth observed in the American Indian population during the 1960-1990 period. Two sets of factors are identified to be responsible for this intragenerational ethnic mobility: socio-demographic factors and sociopolitical factors (Eschbach, Supple and Snipp 1998; Nagel 1998; Eschbach 1993). First, among the American Indians, various people have mixed origins resulting from the exogamy (i.e. intermarriage) of their parents and other ascendants. For these people, the choice of ethnic affiliation may vary according to circumstances and location, but also very likely according to their needs and personal interests. Secondly, American Indian rights defence groups emerged in the 1960s and 1970s. Through their political and community actions, those

CSP 2010, 37.1-2: 151-174 
organizations contributed to removing the social stigma of being identified as American Indian. This renewed pride would have sparked greater interest in reporting American Indian affiliation.

Work done on Aboriginal populations in Australia and New Zealand also showed the presence of intragenerational ethnic mobility. In Australia, Ross (1996) observed that more than half of the Aboriginal population growth observed during the 1991-1996 period can be explained by variations in the quality of population coverage in the census and by changes in self-reporting of ethnic affiliation. In New Zealand, Pool (1991) emphasized, by comparing ethnic origin and identity data, that ethnic mobility contributed to the Aboriginal population's demographic growth since 1926. Like their American colleagues, Ross (1996) and Pool (1991) are of the opinion that political activism and a change in mentality regarding Aboriginal people are two factors which have contributed significantly to the ethnic mobility among Aboriginal populations in Australia and New Zealand.

There is little demographic analysis of intergenerational ethnic mobility among Aboriginal populations in the literature. Studies have generally focused on factors associated with identification patterns of children in Aboriginal families, rather than attempting to measure the impacts of such patterns on the size and structure of Aboriginal populations. For example, Kukutai (2007, 1159), while examining the factors associated with parental decisions regarding ethnic designation of children, found that "racial and ethnic identity is not 'passed' across generations in a predictable, linear fashion". In the United States, Liebler (2004) found that, among the mixed-race part-American Indian children, experiences of race, racial identity, and racial identification depends on the context of their family (e.g., tribal affiliation, complexity of parental heritages) as well as their physical location (e.g., percent of state population that is American Indian). While unquestionably pertinent and informative from the perspective of understanding identification patterns and processes, this type of analytical studies fails to document to what extent intergenerational ethnic mobility actually contributes to the demographic reproduction of Aboriginal populations.

In an effort at methodological conceptualization, Robitaille and Guimond (2003) brought out the necessity to develop the demographic reproduction analysis of Aboriginal populations around the interaction of exogamy, fertility and intergenerational ethnic mobility. As shown in Figure 2, intergenerational ethnic mobility completes a chain of three phenomena affecting the reproduction of a population defined by ethnicity. If a consideration of the interaction between exogamy and fertility enables a better account of the actual fertility of an ethnic group ${ }^{3}$, the actual size of an ethnic group's new generation depends also on intergenerational ethnic mobility. 
Intergenerational Ethnic Mobility

among Canadian Aboriginal Populations in 2001

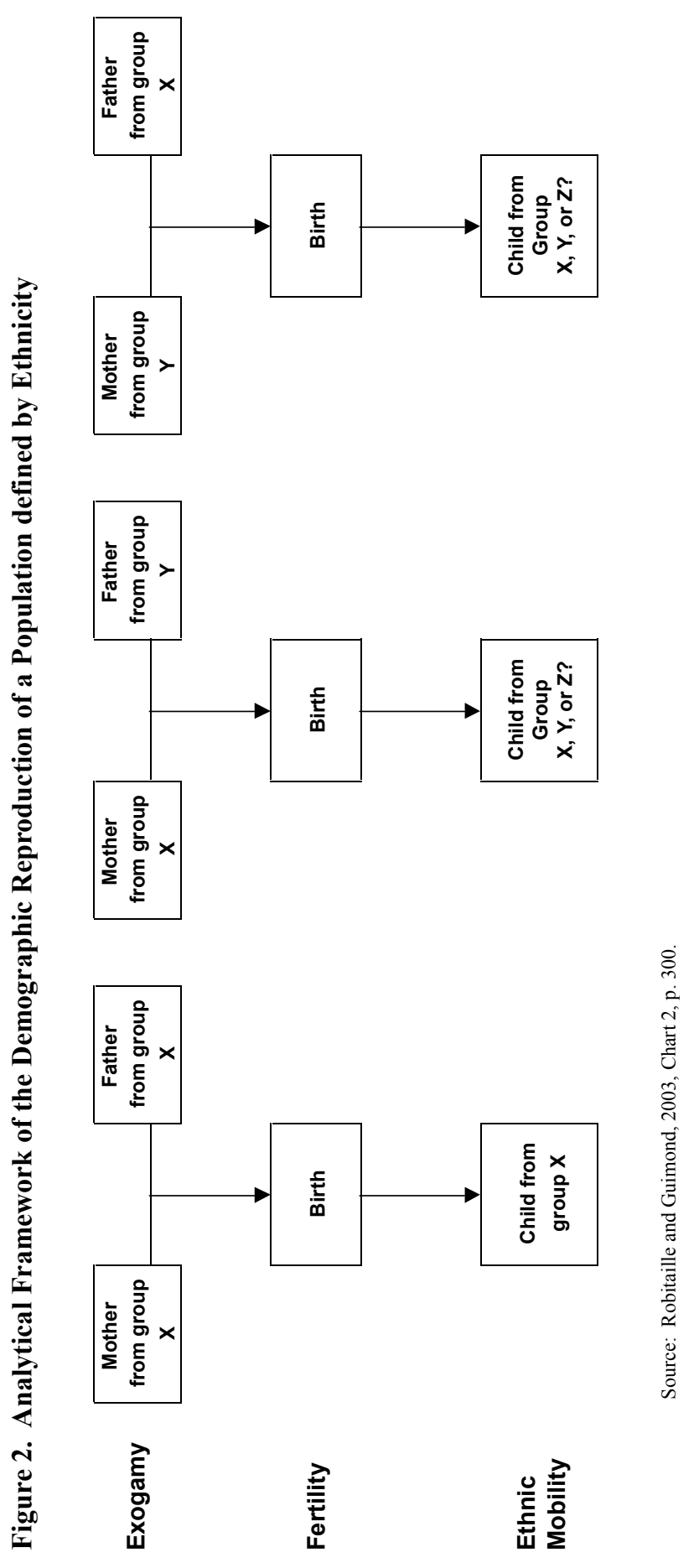

CSP 2010, 37.1-2: 151-174 
The descriptive analysis that follows measures the patterns of intergenerational ethnic identification and mobility of children in Canadian Aboriginal families. Our purpose is to document the contribution of the phenomenon of intergenerational ethnic mobility to the demographic reproduction of Aboriginal populations in Canada. This study builds on work first introduced at 2005 conference of the International Union for the Scientific Study of Population (IUSSP) in France (Robitaille, Boucher and Guimond 2005).

\section{Data}

Analysis of the intergenerational ethnic mobility of Aboriginal groups in Canada relies on a comparison between the ethnic identity of children and that (those) of their parent(s). For most of Canada however, vital statistics in general, and those on births in particular, do not include Aboriginal or ethnic identifiers ${ }^{4}$. As a result, an estimate of intergenerational ethnic mobility among Aboriginal groups is only possible through the Canadian censuses conducted every five years.

For this study, we focused on children under the age of five in 2001 living in a husband/wife (married or common-law) census family. Because the biological link between members of a family is not captured through the Canadian census, our working assumption is that the identified husband and wife are the biological parents of the child. Children living in a family with a single parent or a same-sex couple are excluded from the analysis since the ethnic identity of the missing parent is unknown. In 2001, 15.2\% of Canadian children under the age of five in a census family were living with a single parent or in a same-sex couple family. For Aboriginal children, this proportion reached $37.9 \%$. It should also be noted that the way data were collected in the 2001 Census of $\mathrm{Canada}^{5}$ results in the classification of individuals as either Aboriginal (North American Indian, Métis and/or Inuit) or non-Aboriginal: it was impossible for someone to report both an Aboriginal and a non-Aboriginal identity, but self-reporting of multiple Aboriginal identities was allowed (see Appendix 1).

\section{Analysis}

Figuret 3 shows the proportion of children under the age of five in husband/wife census families by the Aboriginal identity - North American Indian, Métis or Inuit - of their parent(s) (left column) and the type of union in 2001. The nonAboriginal identity is left out because of its disproportionate demographic weight in relation to Aboriginal identities.

CSP 2010, 37.1-2: 151-174 
Intergenerational Ethnic Mobility among Canadian Aboriginal Populations in 2001

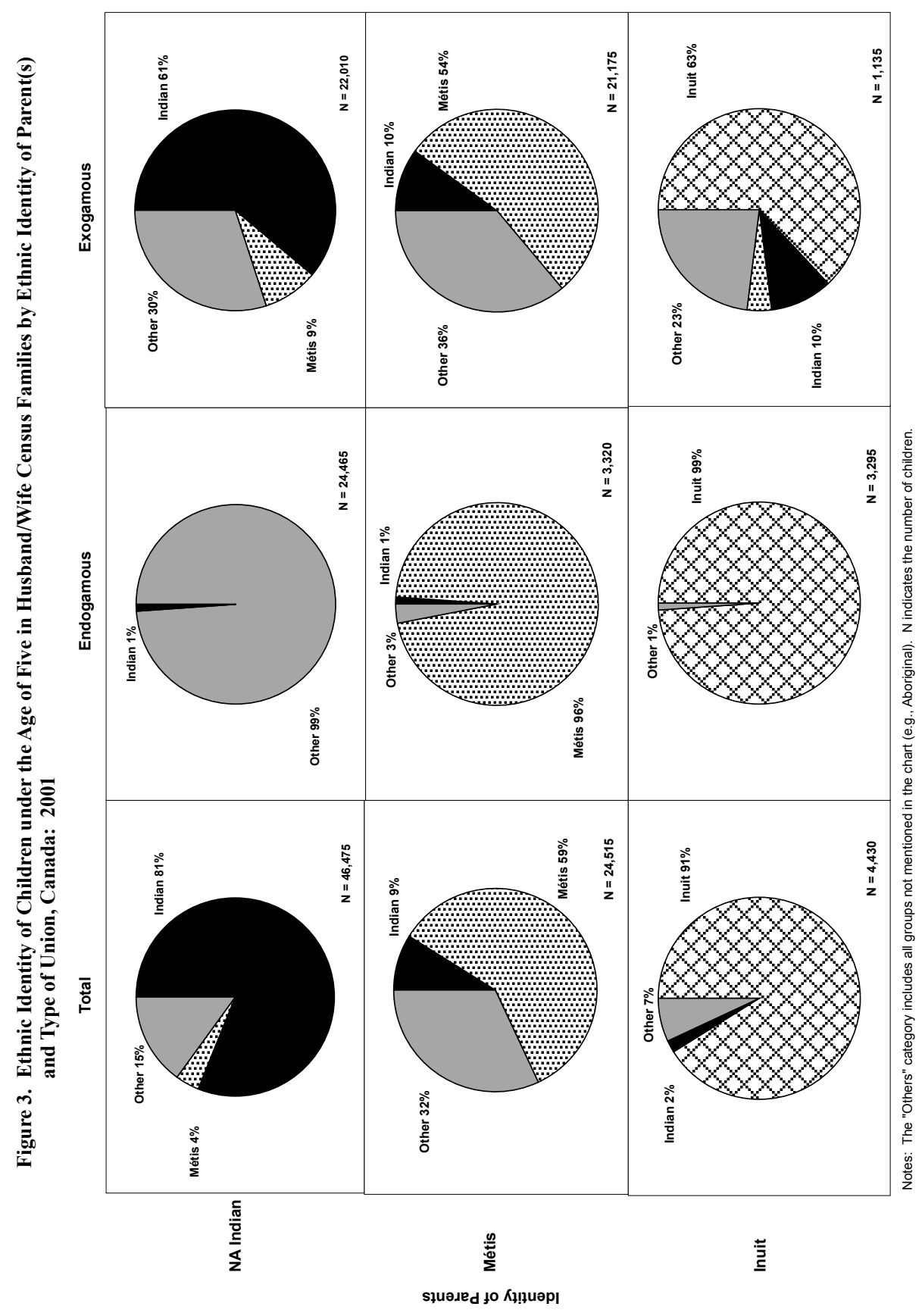

CSP 2010, 37.1-2: 151-174

161 
In total, that is to say for all types of unions taken together, the ethnic identity of the child corresponds most often to that of the Aboriginal parent. As expected, the proportion of children whose ethnic affiliation coincides with that of the Aboriginal parent is much higher in the context of an endogamous union than of an exogamous union. For endogamous Indian, Métis or Inuit unions, at least $96 \%$ (endogamous Métis unions) of children are reported as having their parents' identity. For exogamous unions however, the proportion of children with their Aboriginal parents' identity varies between 54\% (exogamous Métis unions) and 63\% (exogamous Inuit unions).

Intuitively, one could interpret such data on the identification of children according to the type of union as a signal that the interaction between exogamy, fertility and intergenerational ethnic mobility negatively affects the demographic reproduction of Aboriginal groups in Canada. Do we not indeed see that only $61 \%$ of children from Indian and non-Indian parents are identified as Indians, whereas $99 \%$ of children from two Indian parents are identified as Indians? Such an interpretation would be erroneous since the benchmark for evaluating the negative (or positive) nature of the interaction between those three phenomena varies according to the type of union. For endogamous unions, it is expected that $100 \%$ of children with both parents belonging to group $\mathbf{A}$ will also be identified as belonging to group A. As observed on Figure 3, Aboriginal groups display percentages slightly below 100\% (e.g., Métis $96 \%$ ), but this difference can be explained primarily by the presence of step parent $(\mathrm{s})^{6}$. For children from exogamous unions, given the presence of two distinct parental identities (A, B), if these two identities are equally "attractive", it is expected that only $50 \%$ of the children would be identified as belonging to group $\mathbf{A}^{7}$. Quite contrary to popular wisdom, all three Aboriginal groups attract into their group more than half of the children from mixed parentage, while the non-Aboriginal group (not shown on Figure 3) attracts less than $50 \%$ of such children. Interestingly, Kukutai in New Zealand (2007) and Liebler in the United States (2004) also observed a higher propensity of parents of Aboriginal and non-Aboriginal heritage (exogamous unions) to report their child as Aboriginal (as a whole or in combination to another identity).

Figure 4 illustrates the identification patterns of children (represented by ovals) under the age of five in 2001, born in exogamous unions (represented by grey boxes). Arrows and numbers in italics (e.g., 11,220) indicate the number of children "moving" from a particular ethnocultural background (e.g., Indian and non-Aboriginal) to a designated identity group (e.g., Indian). Numbers in ovals indicate the total number of children with the designated identity (e.g., Métis 12,330), born to all exogamous unions represented on the figure. The purpose of this figure is to describe « intergenerational flows » between identity groups. 
Figure 4

Identification Patterns of Children under the Age of Five

Living in Exogamous Unions', Canada: 2001

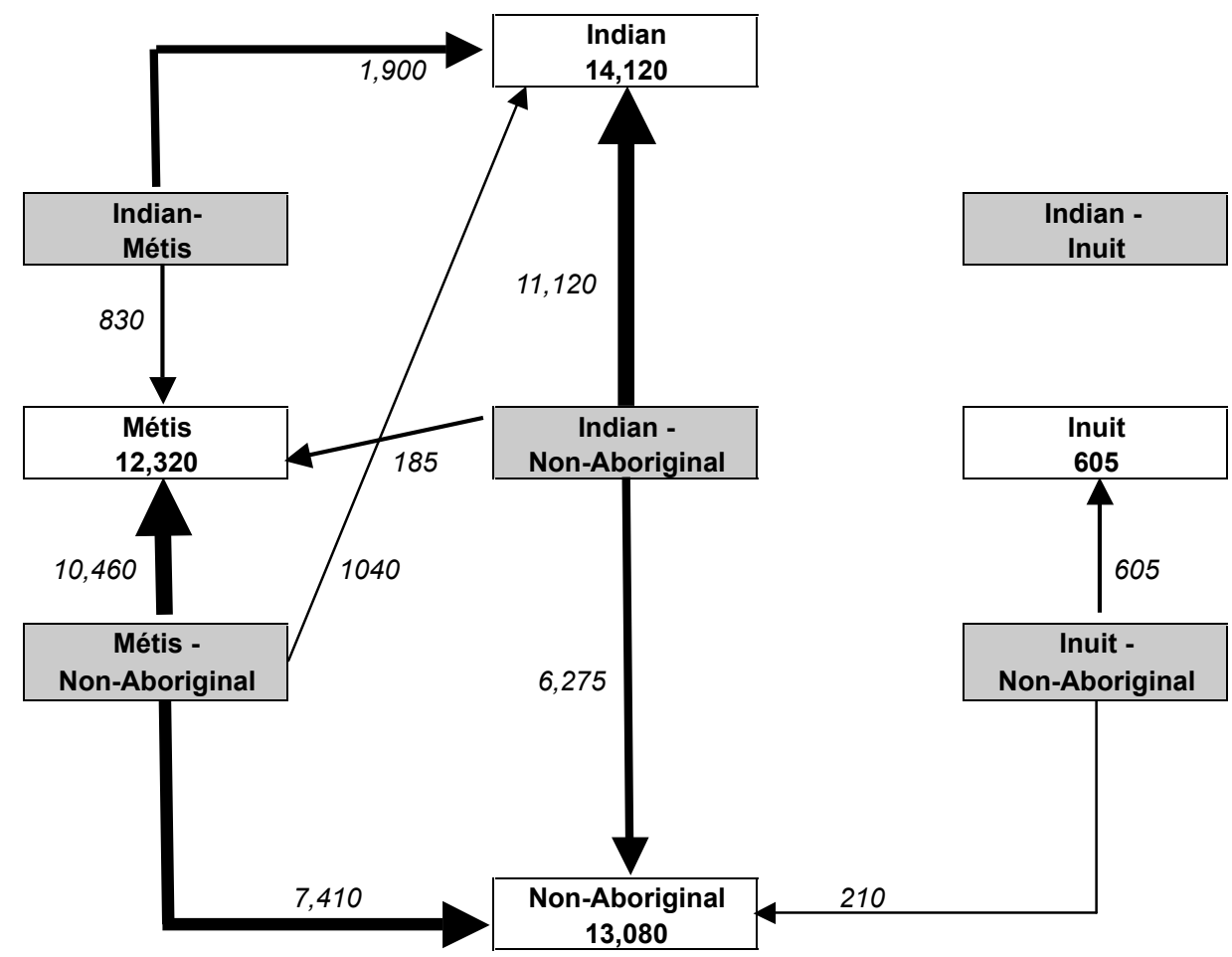

Note: ${ }^{1}$ Includes only identification patterns which accounts for 175 children or more.

Source: Statistics Canada, 2001 Census of Canada, custom tabulations. 
A first scan of this figure reveals that Aboriginal identities are more 'attractive' than non-Aboriginal identity for children born in mixed Aboriginal/non-Aboriginal unions. The Indian identity displays the most favourable results in net absolute terms $(+4,945)$, with 11,220 children identified as Indians, against 6,275 identified as non-Aboriginals. As expected, the net results $(+3,050=10,460-7,410)$ is somewhat smaller for Métis. Even though numbers are much smaller, the Inuit identity also benefits $(+395=605-310)$ from identification preferences for children in mixed unions.

On closer look at Figure 4, one also notices that 1,040 children born to Indian and non-Aboriginal parents are identified as Indians, exceeding by far the number of Indian children from Métis and non-Aboriginal parents (185). It therefore appears that the offspring of Indian/non-Aboriginal couples continue to supply the Métis group, thereby extending the demographic dynamics at its origin.

Figure 5 provides a "demographic report" of children under the age of five in 2001 through the use of a scale representation of the distribution of children by Aboriginal identity of children (North American Indian, Métis or Inuit) and parents (endogamous, exogamous or "unaffiliated" unions). If we suppose that, between birth and the time of the census, deaths, migration and intragenerational ethnic mobility of children and their parent(s) are negligible, we have here a measure of intergenerational ethnic mobility. Children of endogamous unions are those children whose both parents have the identity with the associated Aboriginal group. Exits are children of endogamous unions with an identity different than their parents' Aboriginal identity. Entries are children having the Aboriginal identity of the associated group, whose two parents do not have this identity. The contribution of exogamy is in the form of children with the ethnic identity of only one of their parents. Finally, for each identity, the Total number of children represents all children under the age of five belonging to the specified Aboriginal group.

This figure clearly shows that the Métis are those who, numerically speaking, benefit the most from their own exogamy and identification patterns since it provides them with three times more children than for than endogamous couples $(11,335$ versus 3,340$)$. Among the Indians, such an influx originating from exogamous unions remains significant but is much lower than for endogamous unions $(13,460$ versus 24,465$)$. Among the Inuit, the influx is low compared with the other two groups ( 720 versus 3,295$)$. In comparison, exits and entries involve a smaller number of children: in the case of the Métis, 1,765 children under the age of five are born to parents belonging to another ethnic group. As previously indicated in Figure 4, the vast majority of the contribution of exogamy and entries for each Aboriginal group involves non-Aboriginal parents.

CSP 2010, 37.1-2: 151-174 


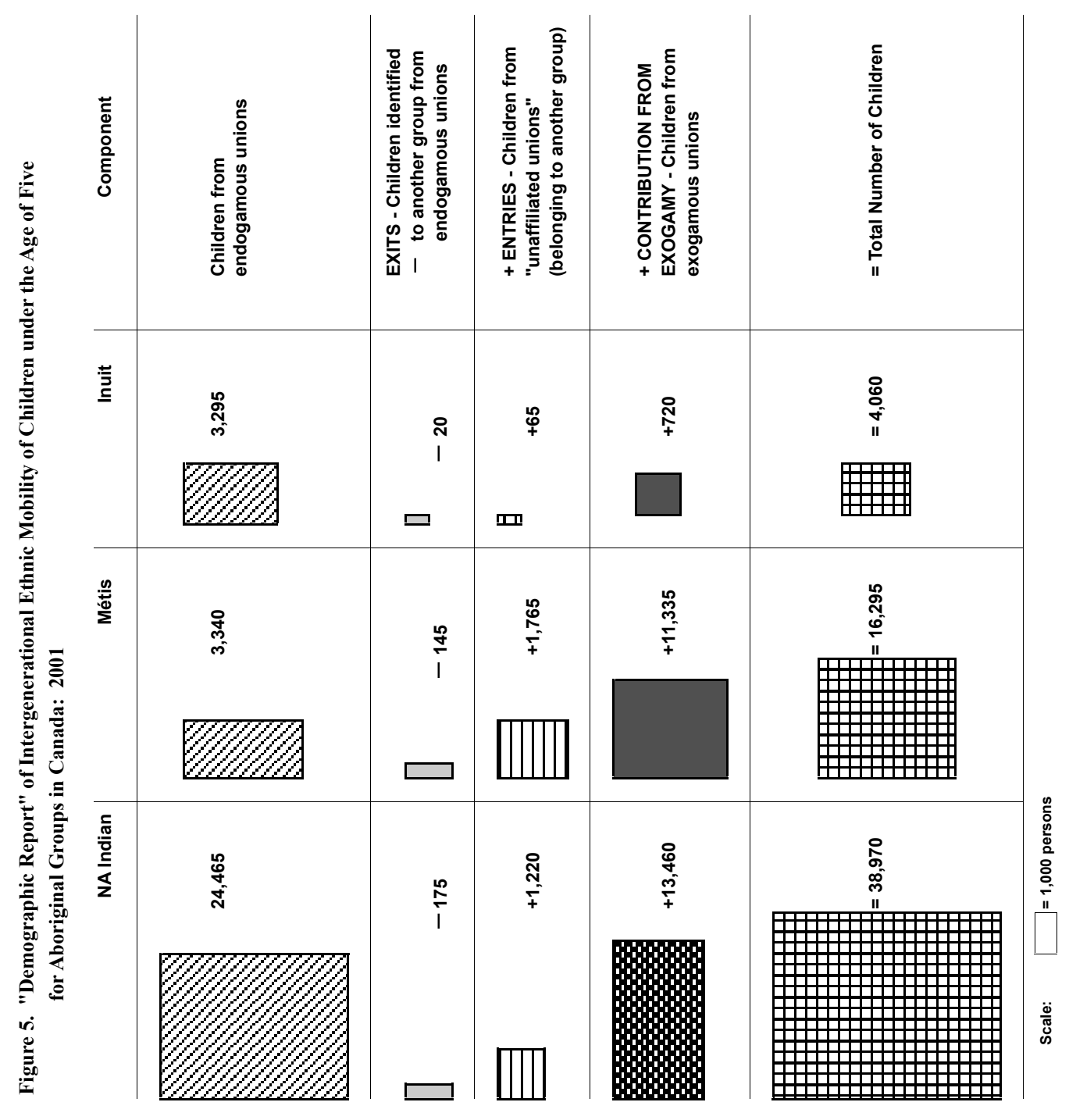


Lastly, Figure 6 shows the distribution of children under the age of five according to the type of union of parents and the Aboriginal identity of the child. It restates the essentials of the information in Figure 5, bringing out the specific composition of each Aboriginal group. Whereas among the Indians $(62 \%)$ and the Inuit $(80 \%)$ most children come from endogamous unions, among the Métis only $20 \%$ come from such unions. The proportion of children from exogamous unions observed among the Métis (69\%) is twice that of Indians (35\%) and almost four times that of Inuit (18\%). In addition, $11 \%$ of Métis children come from couples with no Métis identity. Among the Indians and the Inuit, the corresponding percentage is only $3 \%$ and $2 \%$. Clearly, if Aboriginal identities were "not attractive" identities when in situations of exogamous and "unaffiliated" unions, then the size of the Aboriginal population would be significantly smaller.

\section{Conclusion}

To understand the demographic growth of Aboriginal groups in Canada, it is essential to consider ethnic mobility. On the basis of this first study on the intergenerational ethnic mobility among Aboriginal groups in Canada, it was possible to observe two significant facts. First, in endogamous unions, there is little intergenerational ethnic mobility: children and their parents generally belong to the same ethnic group. Second, similar to what has been found among the Aboriginal populations of New Zealand (Kukutai 2007) and the United States (Liebler 2004), Aboriginal identities are more "attractive" than a nonAboriginal identity for children from an exogamous Aboriginal/non-Aboriginal union. If Aboriginal identities were not "attractive" at all in situations of exogamous unions, the number of North American Indian and Métis children would have been smaller by $35 \%$ and $69 \%$ respectively.

This second finding also points to the Métis group's distinctiveness in two respects. Firstly, children with a Métis identity are mainly from exogamous unions, whereas, for North American Indians and the Inuit, they are mostly from endogamous unions. Secondly, one Métis child in nine comes from an "unaffiliated" union where neither parent is of Métis identity: in most cases, the respective identities of the parents are Indian and non-Aboriginal. At first glance, this distinctiveness of Métis identity could be interpreted as the continuation of the group's history, which is a blend of non-Aboriginal and Aboriginal people and which, in the $19^{\text {th }}$ century, developed a truly autonomous culture, not benefiting however from much recognition before 1982, when the Constitution of Canada explicitly recognized the Métis on the same level as Indians and the Inuit. Unfortunately, it is not possible with the data used for this study to separate the "socio-historical phenomenon" from the "statistical 
Figure 6

Distribution of Children under the Age of Five according to the Type of Union of Parents by Aboriginal Identity of the Child, Canada: 2001

North American Indian

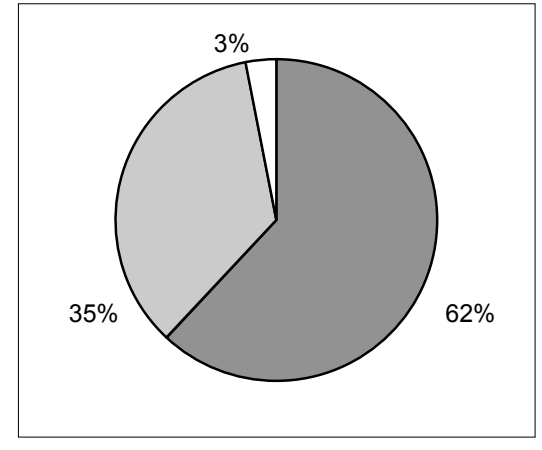

38,970

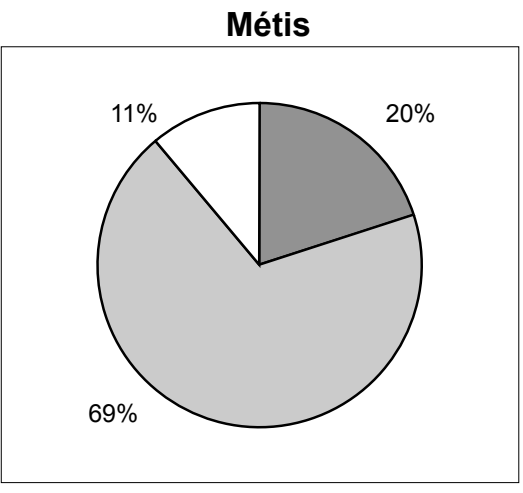

16,295

Inuit

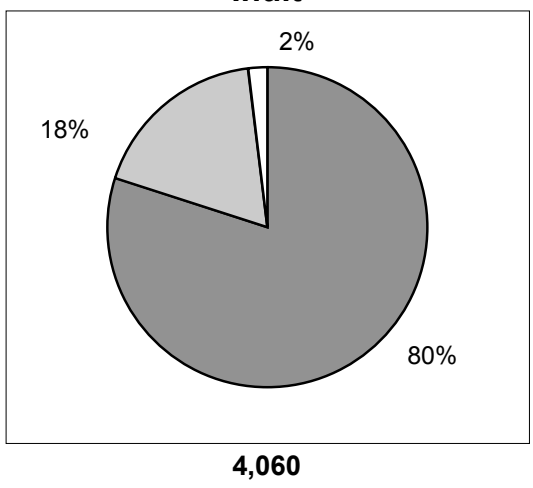

Endogamous Unions

Exogamous Unions

"Unaffiliated" Unions

Source: Statistics Canada, 2001 Census of Canada, custom tabulations. 
artefact" caused by the classification of Aboriginal peoples in the 2001 Census of Canada. Because it was impossible for someone to report both an Aboriginal and a non-Aboriginal identity, some might have self-reported a Métis identity as a way to express their dual identity (i.e., Aboriginal and non-Aboriginal). This constraint of the classification system used in the canadian census should be investigated further. Prior studies of identification patterns among other Aboriginal populations (Kukutai 2007; Liebler 2004) suggest that where selfreporting as Aboriginal and non-Aboriginal is possible, parents often avail themselves of this option. Exploring the dynamics between self-reported origin(s) and self-reported identity(ies) of children in exogamous families could shed additional light to the actual meaning of self-reporting Métis identity.

Finally, existing literature on the relationship between patterns of Aboriginal identification of children by the place of residence of family, but also the gender and ethnic identity of the parent filling out the census form, points to the need to expand this analysis further (Kana'Iaupuni and Liebler 2005; Liebler 2004; Liebler and Kana'Iaupuni 2003). The multicultural composition of Canadian cities will undoubtedly be fertile ground for future intergenerational ethnic mobility. In all likelihood, a growing number of city-dwellers of different ethnocultural affiliations, including Aboriginal persons, will form couples, raise children and become multicultural families. How the children of these "mixed" families are raised from an ethnocultural perspective will have a considerable impact on the ethnic makeup of our cities, Aboriginal populations and Canadian society in general.

\section{Acknowledgement}

Responsibility for any errors rests with the authors.

\section{End Notes}

1. When it was first introduced by Guimond (1999: 188).

2. Various terms are used in the literature to designate this phenomenon: assimilation, ethnic switching, passing, changing identitites, changes in self-reporting of ethnic identity.

3. When the fertility of Aboriginal peoples is compared to that of the general population following the conventional demographic approach, there is a bias introduced: the fertility of the entire population includes all births, whereas Aboriginal births include only births to Aboriginal 
Intergenerational Ethnic Mobility

among Canadian Aboriginal Populations in 2001

women. Births from Aboriginal men whose partners are non-Aboriginal are not included in the calculation of Aboriginal fertility. Thus, the fertility analysis of Aboriginal women only does not make it possible to get a good overview of the renewal capacity of Aboriginal populations, both men and women. See Robitaille and Guimond (2003), and Norris, Clatworthy and Guimond (2001).

4. With the exception of British Columbia, Manitoba and Nunavut.

5. First introduced in the 1996 Census of Canada. See Statistics Canada, 2004, pp. 43-44

6. For example, an Indian woman who had a child with a non-Aboriginal man but is now living with an Indian man, could be classified as living in an Inddian endogamous union with a non-Aboriginal child.

7. $50 \%$ would be identified as belonging to Group B.

\section{References}

Alba, R. 1990. Ethnic Identity: The Transformation of White America. New Haven and London: Yale University Press.

Barth, F. 1969. Ethnic Groups and Boundaries. Boston: Little Brown.

Castonguay, C. 1977. "La mobilité ethnique au Canada." Recherches sociographiques 18(3): 431-450.

Eschbach, K. 1993. "Changing identification among American Indians and Alaska Natives.” Demography 30(4): 635-652.

Eschbach, K., K. Supple and C. M. Snipp. 1998. "Changes in Racial Identification and the Educational Attainment of American Indians, 19701990." Demography 35(1): 35-43.

Gordon, M. M. 1964. Assimilation in American Life. The Role of Race, Religion, and National Origins. New York: Oxford University Press.

CSP 2010, 37.1-2: 151-174 
Guimond, E. 1999. "Ethnic Mobility and the Demographic Growth of Canada's Aboriginal Populations from 1986 to 1996," in Report on the Demographic Situation in Canada. Ottawa: Statistics Canada, Catalogue no. 91-209-XPE: 187-200.

Guimond, E. 2003. "Changing Ethnicity: The Concept of Ethnic Drifters," in:Aboriginal Conditions: Research Foundations for Public Policy. J. White, P. Maxim and D. Beavon (eds.), Vancouver: UBC Press. Pp. 91-107.

Guimond, E. 2009. L'explosion démographique des populations autochtones $d u$ Canada de 1986 à 2001, Ph.D. thesis. Université de Montréal, Département de démographie.

Kana' Jaupini, S. M. and C. A. Liebler. 2005. "Pondering poi dog : Place and racial identification of multiracial native Hawaiians." Ethnic and Racial Studies 28(4): 687-721.

Kukutai, T. H. 2007. "White mothers, brown children : Ethnic identification of Maori-European children in New Zealand." Journal of Marriage and Family 69: 1150-1161.

Henripin, J. 1974. L'immigration et le déséquilibre linguistique. Ministère de la Main-d'oeuvre et de l'Immigration du Canada, Ėtude sur l'immigration et les objectifs démographiques du Canada.

Lieberson, S. and M. C. Waters. 1988. From Many Strands: Ethnic and Racial Groups in Contemporary America. New York: Russell Sage Foundation, Census Monograph Series.

Liebler, C. A. 2004. "Ties on the Fringes of Identity." Social Science Research 33: 702-723.

Liebler, C. A. and S. M. Kana'Iiapuni. 2003. "Pacific identities: Patterns in the racial identifications of mixed-race Pacific Islanders." The Journal of Intergroup Relations 30(4): 23-47.

Nagel, J. 1995. "American Indian ethnic renewal : Politics and the resurgence of identity." American Sociological Review 60: 947-965.

CSP 2010, 37.1-2: 151-174 
Intergenerational Ethnic Mobility

among Canadian Aboriginal Populations in 2001

Norris, M. J., S. Clatworthy and E. Guimond. 2001. Demography, Legislation and Ethnic Mobility: Considerations and Implications for Projections of Canada's Aboriginal Populations. Paper presented at the 2001 annual meetings of the Population Association of America, Washington.

Passel, J. S. 1976. "Provisional evaluation of the 1970 Census count of American Indians.” Demography 13(3): 397-409.

Passel, J. S. 1996. "The Growing American Indian Population, 1960-1990: Beyond Demography," in Changing Numbers, Changing Needs: American Indian Demography and Public Health. G. Sandefur, R. Rindfuss and B. Cohen (eds.), National Academy Press, Washington DC. Pp. 79-102.

Passel, J. S. and P. A. Berman. 1986. "Quality of 1980 Census data for American Indians.” Social Biology 33(3-4): 163-182.

Pool, I. 1991. Te Iwi Maori: A New Zealand population past, present and projected. New Zealand. Auckland. Auckland University Press.

Robitaille, N., A. Boucher and É. Guimond. 2005. Intergenerational Ethnic Mobility of Aboriginal Populations in Canada, 1996-2001. Poster presented at International Union for the 2005 Scientific Study of Population (IUSSP) Conference, France, Tours.

Robitaille, N. and R. Choiniére. 1987. "L'accroissement démographique des groupes autochtones du Canada au XXe siècle." Cahiers Québécois de Démographie 16(1): 3-35.

Robitaille, N. and É. Guimond. 2003. "La reproduction des groupes autochtones : Exogamie, fécondité et mobilité ethnique." Cahiers Québécois de Démographie 32(2): 295-314.

Ross, K. 1996. Population Issues, Indigenous Australians. Australia: Australian Bureau of Statistics. Occasional Paper 4708.0.

Ryder, N. B. 1955. "The Interpretation of Origin Statistics." Journal of Economics and Political Science 21(9): 466-479.

Statistics Canada. 2004. 2001 Census Dictionary. Catalogue No. 92-378-XIE. Ottawa: Statistics Canada. 
Appendix 1

Excerpts of the 2001 Census of Canada Long Form Questionnaire

Question \#17: Ethnic Origin

While most people in Canada view themselves as Canadians,

information on their ancestral origins has been collected

since the 1901 Census to capture the changing composition

of Canada's diverse population. Therefore, this question

refers to the origins of the person's ancestors.

17 To which ethnic or cultural group(s) did this person's ancestors belong?

For example, Canadian, French, English, Chinese Italian, German, Scottish, Irish, Cree, Micmac, Métis, Inuit (Eskimo), East Indian, Ukrainian,

Dutch, Polish, Portuguese, Filipino, Jewish, Greek,

Jamaican, Vietnamese, Lebanese, Chilean,

Somali, etc.

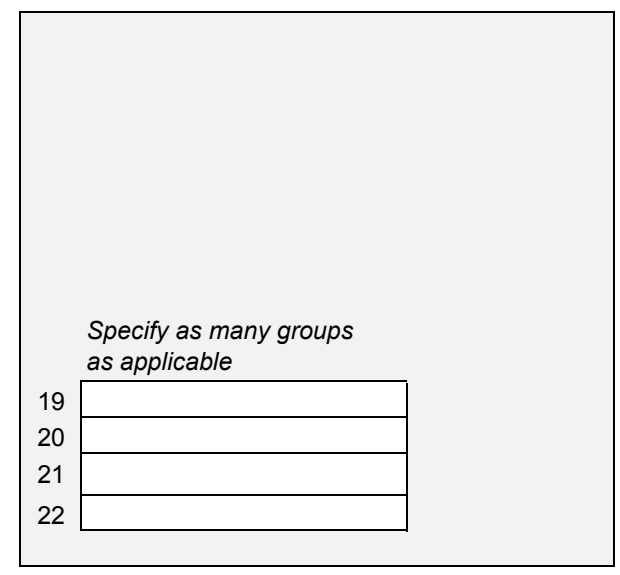

Question \#18: Aboriginal Identity

18 is this person an Aboriginal person, that is, North American Indian, Métis or Inuit (Eskimo)?

If "Yes", mark "x" the circle(s) that best describe(s) this person now.

\begin{tabular}{|c|c|c|}
\hline 19. & No $>$ & $\begin{array}{l}\text { Continue } \\
\text { with the next } \\
\text { question }\end{array}$ \\
$02 \bigcirc$ Yes, North \\
American Indian \\
$03 \bigcirc$ Yes, Métis \\
04 & Yes, Inuit (Eskimo)
\end{tabular}

Source: Statistics Canada, 2004 
Intergenerational Ethnic Mobility among Canadian Aboriginal Populations in 2001

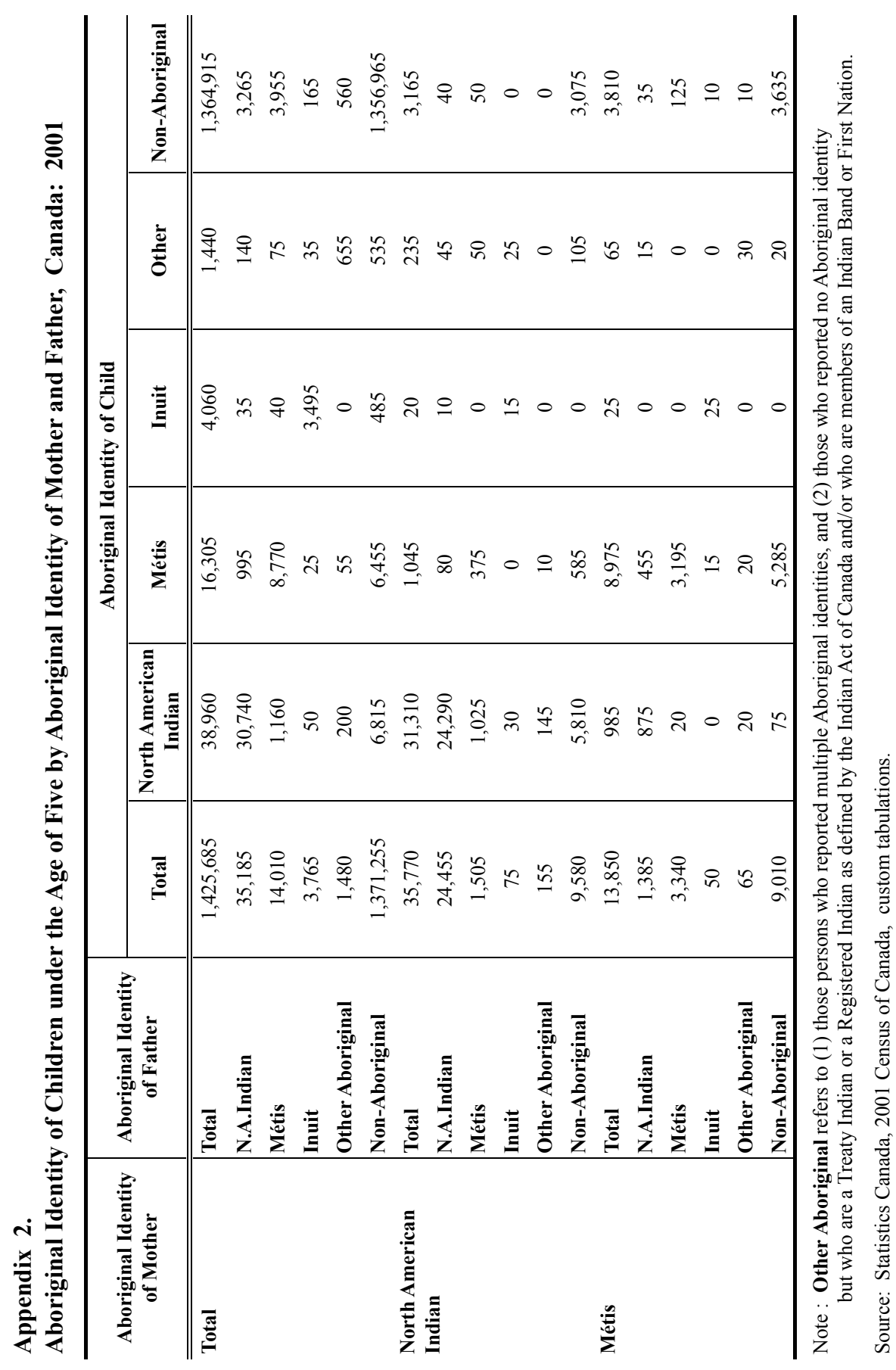

CSP 2010, 37.1-2: 151-174

173 


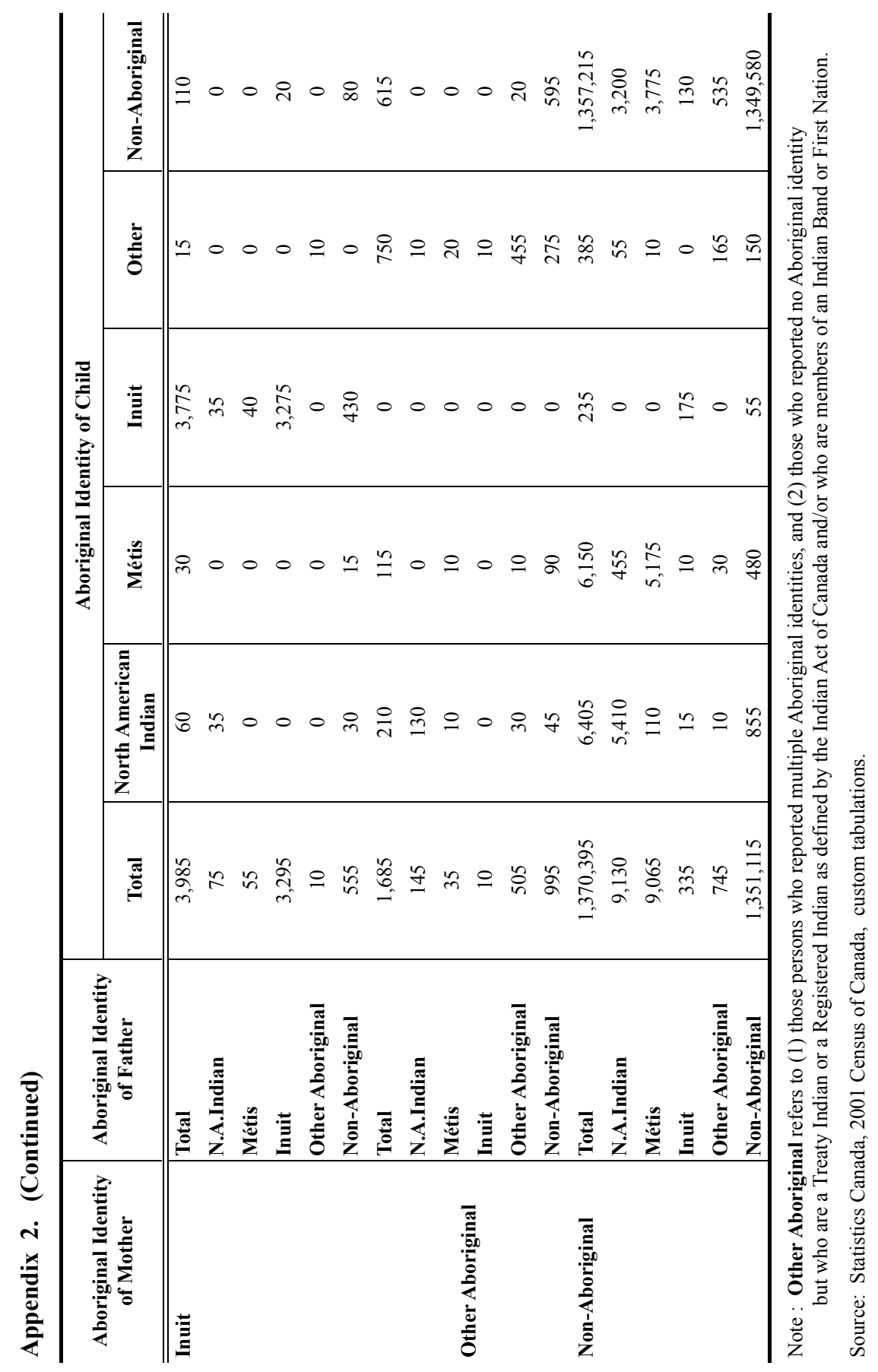

CSP 2010, 37.1-2: 151-174

174 